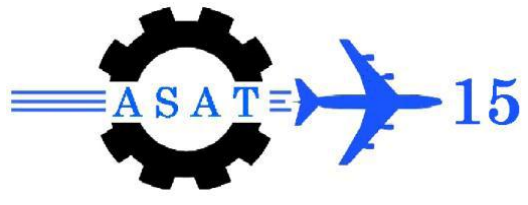

\title{
Primary Trainer Aircraft Conversion to UAV Configuration
}

\author{
A. A. Ismail ${ }^{*}$, M. E. Elsayed ${ }^{\dagger}$
}

\begin{abstract}
Multiple uses and missions of any newly designed aircraft would be beneficial to increase its market as it offers the manufacturers opportunities to sell more units of it; therefore, the designers develop their aircraft in a way to increase the company market-share according to continuously changing customer expectations by designing a multi-mission vehicle. In this paper a typical light aircraft (Safat01), which is being produced in Sudan, will be analyzed from the point of view of its configuration, aerodynamic characteristics and the internal space offered by cross-section of fuselage to integrate the desirable payload to determine aircraft suitability to the new mission(s).
\end{abstract}

Safat01 is a primary training aircraft which is intended to be converted to unmanned vehicle for the purpose of mining exploration, a new critical economical issue arising in the country nowadays. Consequently, a comprehensive analysis of its configuration and disposition of main parts of it such as wing, fuselage, etc. is very important - rather crucial - for developing it.

The approach used in this research relies upon exploring the capabilities and geometrical characteristics of Safat01 and then comparing it with similar desirable mission UAVs. The 3D CATIA model of the aircraft has been used in the geometrical characteristics analysis. Standard design considerations have been used for analyzing the aircraft configuration.

Initial results indicated the suitability of Safat01 for the new mission because of its good performance and handling qualities which are the results of the good configuration. The aircraft has shown acceptable characteristics to be used for the intended mission.

Keywords: light aircraft, mining exploration, UAV civilian application, handling qualities.

\section{Introduction}

Big companies in the world started using UAVs in their exploration and production activities at the beginning of this century. Since that time, some UAVs for mineral exploration have been produced by these companies.

Sudan has huge mineral fortune that needs to be explored. This necessitates finding out the best and fastest way to do such mission. The wide area needed to be surveyed yields that air exploring is preferable. The primary use of aircraft within the mining industry is for exploration; to map out tracts of distant terrain and to explore for potential mineral deposits.

Aeronautical Research Center, North Khartoum, Sudan; Mobile No: +249912515508 bakri8888@hotmail.com

$\dagger \quad$ Aeronautics Dept., College of Engineering, Karary University, Omdurman, Sudan; mohadi20@hotmail.com 
The nature of such missions makes the use of UAVs a natural fit, but that is not the only area of mining operations in which unmanned aircraft excel. For a UAV to be useful in mining exploration it must be able to travel at low altitude over long distances and carry a suitable payload of scientific equipment capable of storing and transmitting information [1]. Safat01 is a primary training aircraft which is considered suitable to perform this mission. If this aircraft could be operated as a mining exploration UAV, then many units could be produced and sold, i.e. a new way of promoting the aircraft. Starting from this point, aircraft configuration analysis should be done at the conceptual phase of development process to verify whether it is suitable for the new mission or not. To prove that, comparison between Safat01 with a mining exploration UAV has been conducted.

\section{General Specification of Safat01}

Table (1) shows the general specifications of Safat01.

Table 1 General specifications of Safat01

\begin{tabular}{l|l}
\hline \hline $\mathrm{W}_{\mathrm{TO}}$ & $700[\mathrm{~kg}]$ \\
\hline $\mathrm{W}_{\mathrm{PL}}$ & $66[\mathrm{~kg}]$ \\
\hline $\mathrm{W}_{\mathrm{F}}$ & $226[\mathrm{~kg}]$ \\
\hline Wing span & $10.6[\mathrm{~m}]$ \\
\hline Wing area & $15.87[\mathrm{~m}]$ \\
\hline Max. level speed & $180[\mathrm{~km} / \mathrm{hr}]$ \\
\hline Cruise speed & $145[\mathrm{~km} / \mathrm{hr}]$ \\
\hline Rate of climb & $7[\mathrm{~m} / \mathrm{s}]$ \\
\hline Absolute ceiling & $3[\mathrm{~km}]$ \\
\hline \hline
\end{tabular}

From the CFD analysis that had been done to Safat01, it is obtained that $C_{L, \max }=1.67$ at $16^{\circ}$ angle of attack [2]. According to general specifications mentioned above, Safat01 will be sized to find out its performance characteristics. The initial sizing calculation process yields the following results:

$$
\begin{aligned}
& \left(\frac{W}{S}\right)_{\mathrm{TO}}=9.0341 \mathrm{Ib} / \mathrm{ft}^{2} \quad \text { see Figure (1) } \\
& \left(\frac{W}{\mathrm{P}}\right)_{\mathrm{T} O}=12.346 \mathrm{Ib} / \mathrm{hp} \quad \text { see Figure (1) } \\
& \mathrm{W}_{\mathrm{TO}}=700 \mathrm{~kg}=1543.238 \mathrm{Ib} \\
& \Rightarrow \quad\left(\frac{W}{p}\right)_{L}=12.346 \Rightarrow \quad P=\frac{1543.236}{12.346}=125 \mathrm{hp} \\
& \Rightarrow \quad\left(\frac{W}{\mathrm{~S}}\right)_{\mathrm{L}}=9.0341 \Rightarrow \mathrm{S}=\frac{1543.236}{9.0341}=170.823 \mathrm{ft}^{2}=15.87 \mathrm{~m}^{2} \\
& \mathrm{P}=\mathbf{1 2 5 ~ h p} \\
& \mathrm{S}=\mathbf{1 5 . 8 7} \mathrm{m}^{2}
\end{aligned}
$$




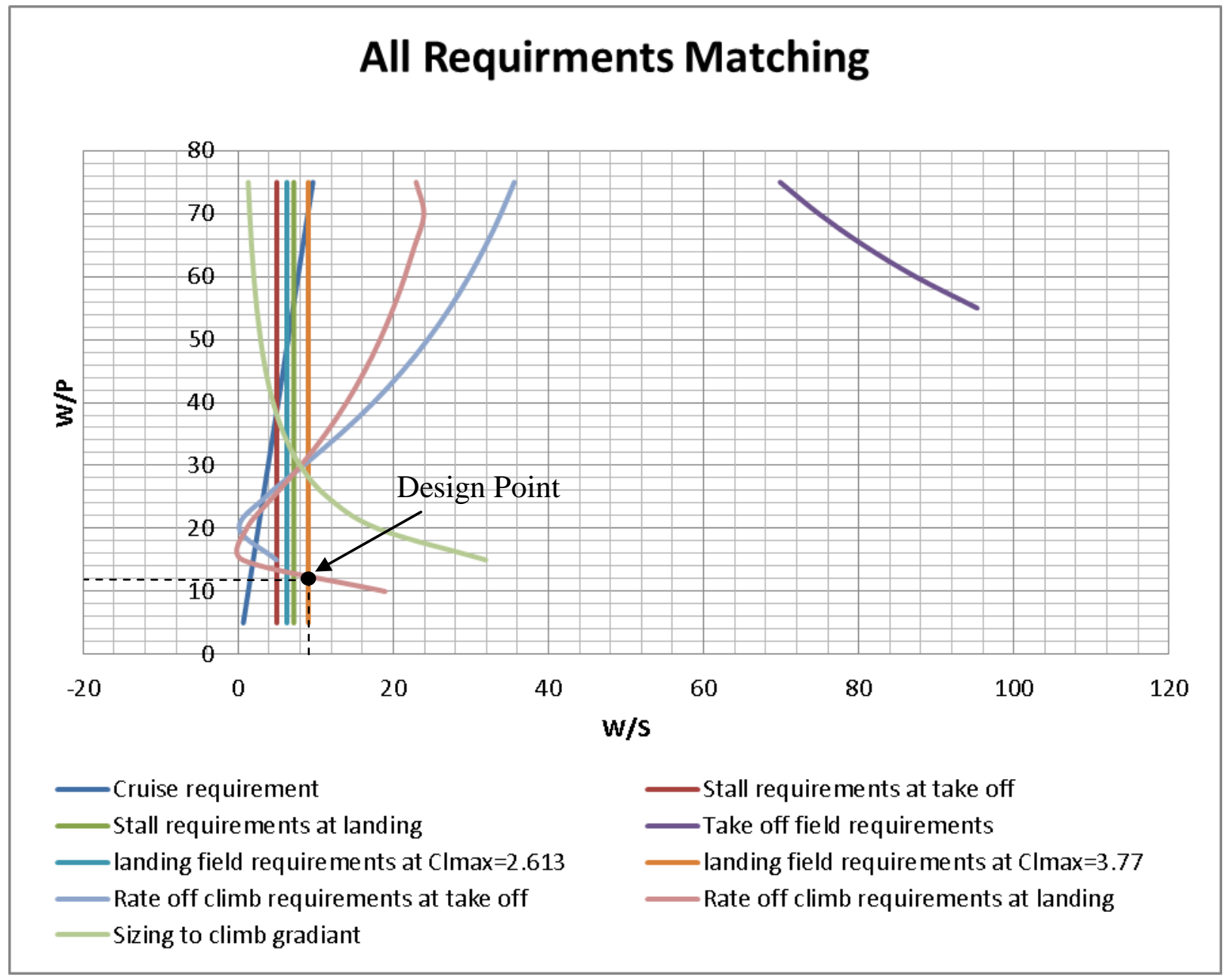

Figure 1 Safat01 initial sizing [3]

\section{Views of Safat01}
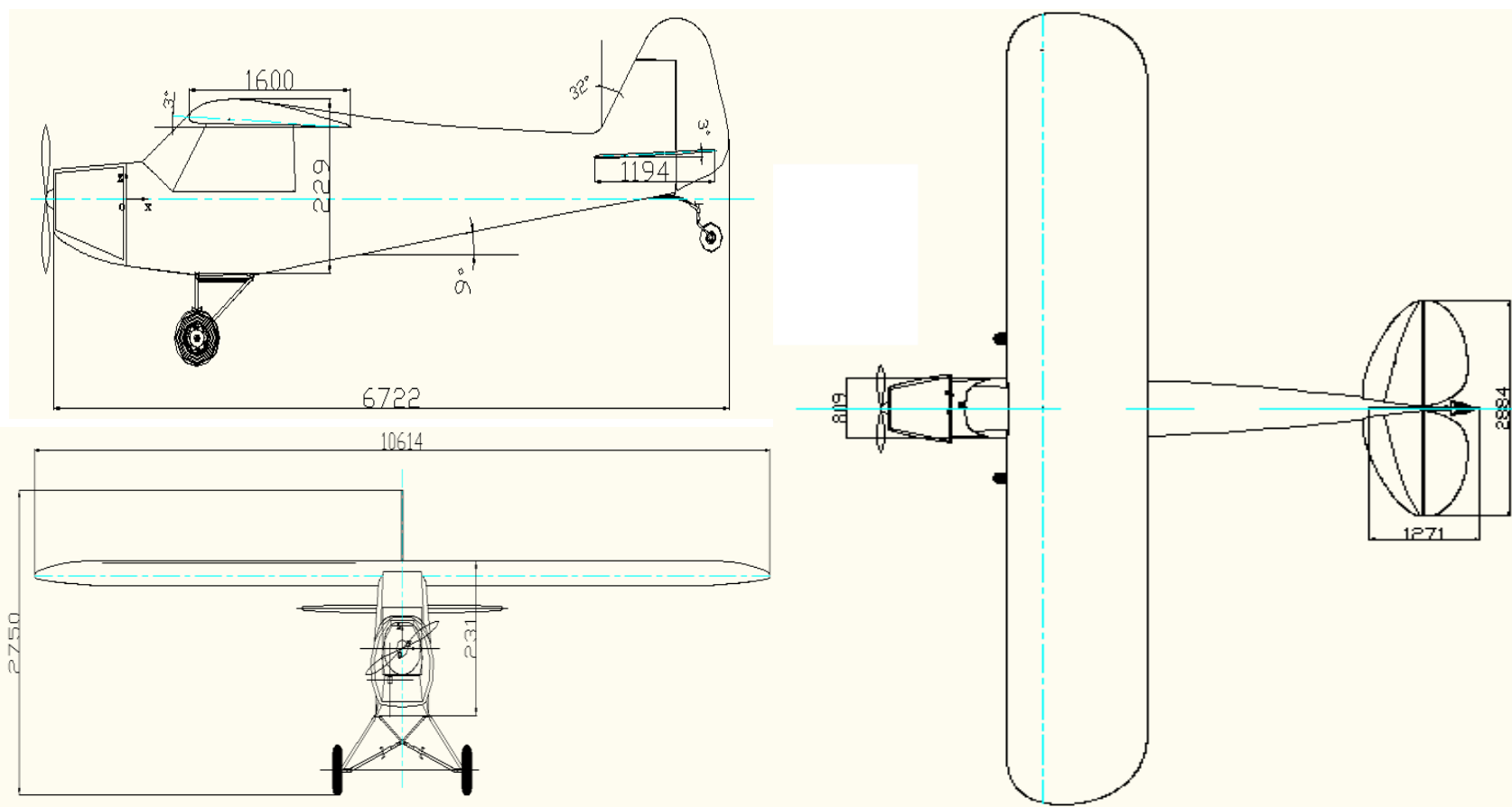

Figure 2 Safat01 3 views 


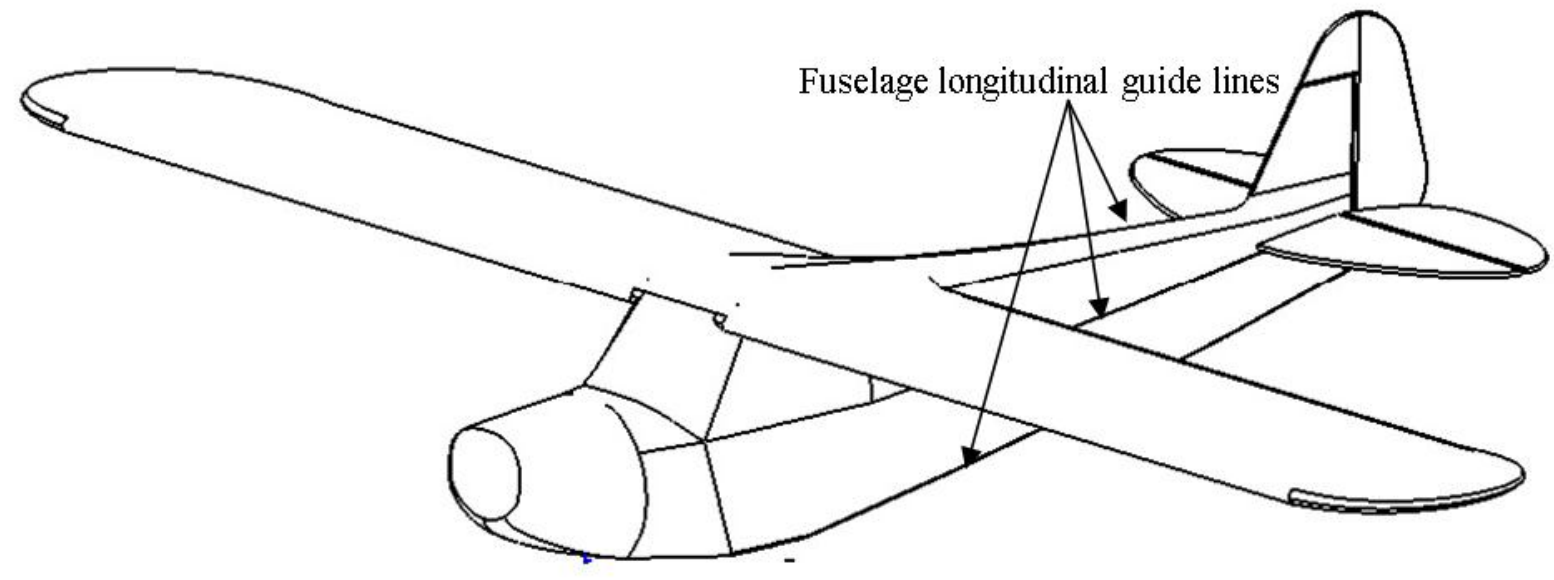

Figure 3 Safat01 Isometric view

\section{Safat01 Configuration Analysis}

The 3 views shown in Figure (2) illustrate the geometrical specifications of Safat01and the isometric view show the theoretical specifications of different parts of the aircraft. Every main part will be studied individually to investigate the strength and weakness points in this design when operating as UAV.

\section{Fuselage}

The cross section of Safat01 fuselage is polynomial -as shown in Figure (2)- which provides enough space to install the required payload to perform mining exploration. The aft fuselage angle is $\left(9^{\circ}\right)$ as shown above which prevents separation of the air flow at low speed and improves the stability of the aircraft. The fuselage shape has been produced from smooth contours as shown in Figure (3) which is a major driver for good aerodynamic design. The fineness ratio of the fuselage is high (about 9.42), so this increases wetted area and leads to increase drag. From aerodynamic viewpoint, the fuselage cross section is drag body and deforms wing span-wise lift distribution [4].

\section{Wing}

It is known that high wing layout is good in lateral stability, but it is heavier than other layouts. The wing drag which is producing a nose-down pitching moment, so it is longitudinally stabilizing. This is due to the higher location of wing drag line relative to the aircraft center of gravity; the a/c trim angle is 2 deg which restrict a/c maneuvering capabilities. Since the engine is tractor layout, the high wing is located away from the wake of the propeller. The parameters of Safat01 wing which are aspect ratio (7.098), taper ratio $(1)$, dihedral angle $\left(0^{\circ}\right)$, incidence angle $\left(3^{\circ}\right)$ and twist angle $\left(0^{\circ}\right)$ show that the wing has been designed for low speed performance [4].

\section{Tail}

Conventional tail unit used in Safat01 gives adequate stability and control. The ellipse shape of the horizontal and vertical stabilizers gives high wetted area which means more stability but more drag also. There is no airfoil of the stabilizers, which means Safa01 cannot perform high maneuvers at high angles of attack [2]. The layout of the horizontal tail is the best, due to avoidance of wing weak, see Figure (4). 


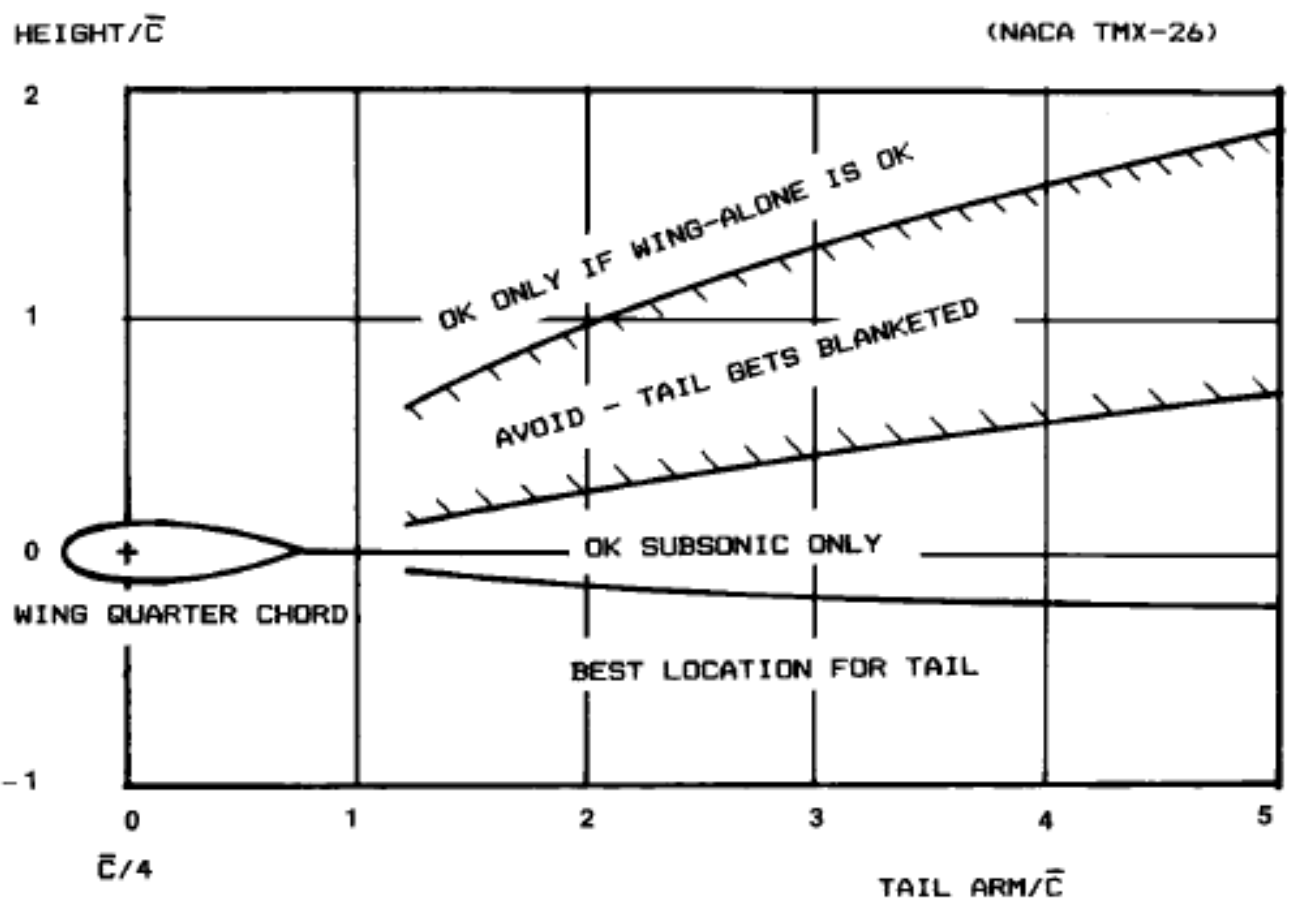

Figure 4 Horizontal tail position [4]

\section{Engine}

The engine is piston engine positioned in front of the fuselage which is called tractor layout. The engine efficiency is high due to taking air flow from free stream directly. The fuselage is located in the propeller down-wash, which affects the lift produced by fuselage and increases its induced drag. The maintenance accessibility is good for this layout. The tractor location propeller puts the heavy engine up front, which tends to shorten the fore body allowing a smaller tail area and improves the stability [4].

The a/c is stable longitudinally and directionally since obtained results shows that $\mathrm{C}_{\mathrm{m} \alpha}<0$; $\mathrm{C}_{\mathrm{N} \beta}>0 .[2]$

\section{Comparison between Safat01 and Mining Exploration UAV}

The mining exploration UAV should fulfill a list of requirements in order to perform this mission properly. Firstly, its low level flying performance should be adequate to get high clear image of scanned territory [5]. Figure (5) shows that Safat01 has good performance characteristics at standard conditions, due to maximum L/D is gained at small angle of attack. Secondly, sufficient flight endurance should be provided by the UAV, 30 hours will be enough for this mission. The useful load carried by the UAV should be considered by the designer, so the UAV can carry mining payloads shown in Table (2).

The capabilities of Safat01 have been compared herein with a mining exploration UAV known as (InView), which is shown in Figure (6), based on the requirements states before. The comparison process will be divided into two divisions. First comparison relay on geometrical specifications shown in Table (3). Second one according to performance characteristics illustrated in Table (4). 
Table 2 Size weight and power of various sensors [6]

\begin{tabular}{c|c|c|c|c|c}
\hline Sensor & Detects & $\begin{array}{c}\text { Passive/ } \\
\text { Active }\end{array}$ & $\begin{array}{c}\text { Weight } \\
(\mathrm{kg})\end{array}$ & $\begin{array}{c}\text { Power } \\
(\mathrm{W})\end{array}$ & $\begin{array}{c}\text { Dimensions } \\
(\mathrm{mm})\end{array}$ \\
\hline SAR & $\begin{array}{c}\text { Reflected } \\
\text { microwaves }\end{array}$ & Active & 0.9 & 15 & $157 \times 191 \times 114$ \\
\hline $\begin{array}{c}\text { Night camera } \\
\text { (IR) }\end{array}$ & Infrared & Passive & 2.9 & 18 & $300 \times 200 \times 200$ \\
\hline $\begin{array}{c}\text { Electro-Optical } \\
\text { camera }\end{array}$ & HD video & Passive & 1.0 & 7 & $180 \times 180 \times 180$ \\
\hline LIDAR & $\begin{array}{c}\text { Reflected } \\
\text { Laser Light }\end{array}$ & Active & 11.5 & 65 & $345 \times 180 \times 180$ \\
\hline $\begin{array}{c}\text { Hyperspectral } \\
\text { camera }\end{array}$ & $\begin{array}{c}\text { Hyperspectral } \\
\text { pictures }\end{array}$ & Passive & 1 & $<10$ & $110 \times 93 \times 50$ \\
\hline $\begin{array}{c}\text { Multispectral } \\
\text { camera }\end{array}$ & $\begin{array}{c}\text { Multispectral } \\
\text { pictures }\end{array}$ & $\begin{array}{c}\text { Passive/ } \\
\text { Active }\end{array}$ & 1.25 & 10 & $92 \times 112 \times 122$ \\
\hline $\begin{array}{c}\text { Chemical } \\
\text { warfare sensor }\end{array}$ & $\begin{array}{c}\text { Nerv gases, } \\
\text { Blister agents }\end{array}$ & Passive & 0.016 & 0.5 & $150 \times 150 \times 150$ \\
\hline $\begin{array}{c}\text { Metal Oxide } \\
\text { sensor }\end{array}$ & Ozone & Passive & 0.7 & 1 & $135 \times 225 \times 260$ \\
\hline Cell Spotter & $\begin{array}{c}\text { Communication } \\
\text { Signals }\end{array}$ & $\begin{array}{c}\text { Passive/ } \\
\text { Active }\end{array}$ & 1.1 & 7 & $40 \times 208 \times 141$ \\
\hline \hline
\end{tabular}

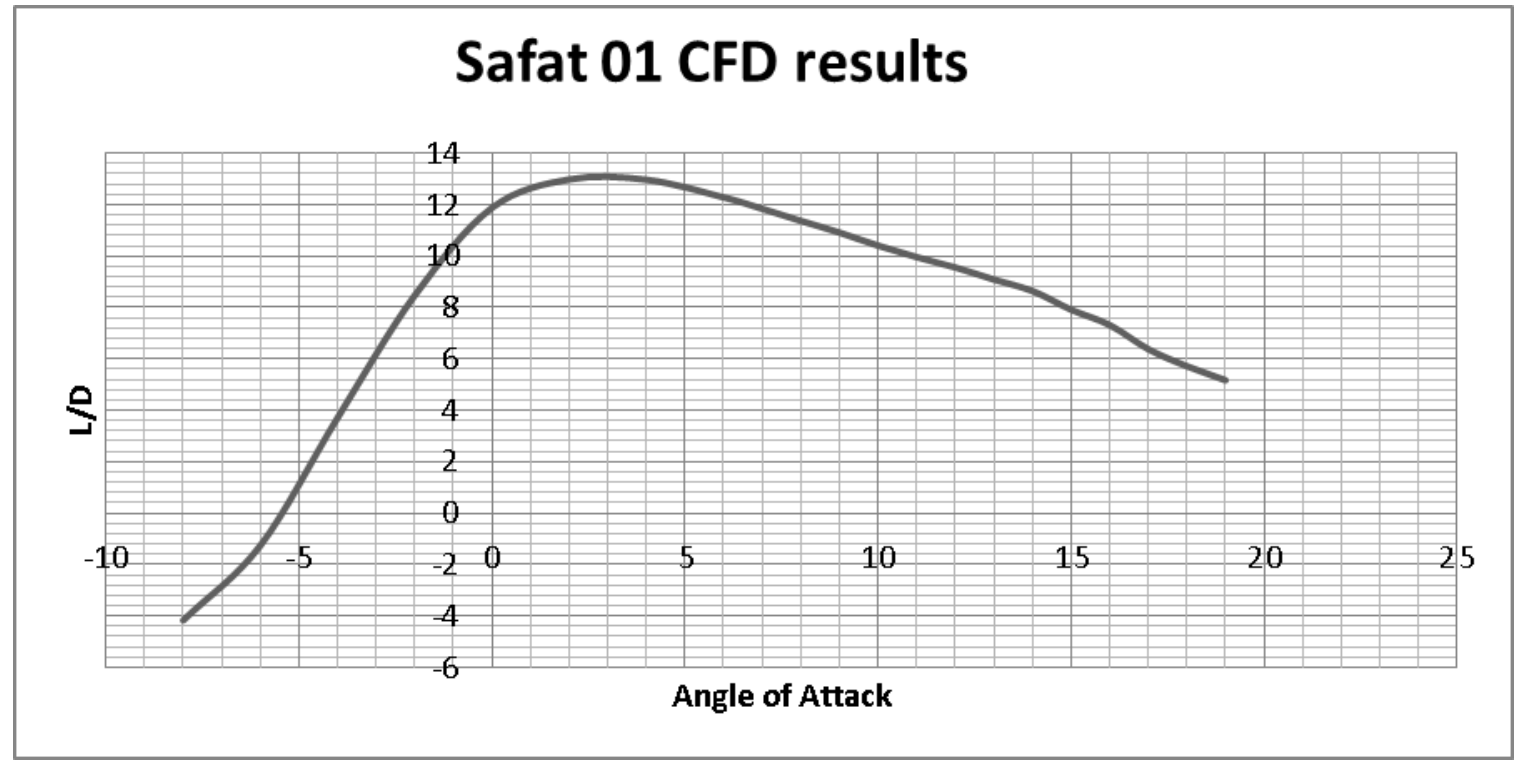

Figure 5 Safat01 CFD results about L/D [2] 
Table 3: Geometrical comparison between Safat01 and InView

\begin{tabular}{c|c|c|c}
\hline \hline $\begin{array}{c}\text { Maximum takeoff } \\
\text { weight }\end{array}$ & Safat01 & InView[4] & observation \\
\hline Payload weight & $600[\mathrm{~kg}]$ & Less than $20[\mathrm{~kg}]$ & $\begin{array}{c}\text { Safat01 is much } \\
\text { more heavier }\end{array}$ \\
\hline Fuselage cross section & Polynomial & $\begin{array}{c}\text { Square with fillet } \\
\text { corners }\end{array}$ & $\begin{array}{c}\text { Safat01 can carry } \\
\text { more payload }\end{array}$ \\
\hline Wing layout & $\begin{array}{c}\text { Rectangular with } \\
\text { elliptical wing tips }\end{array}$ & Rectangular \\
\hline Tail layout & $\begin{array}{c}\text { Conventional } \\
\text { elliptical tips }\end{array}$ & Conventional & nearly the same \\
\hline Propulsion & $\begin{array}{c}\text { One piston tractor } \\
\text { front fuselage engine } \\
\text { provides 125 [hp] }\end{array}$ & $\begin{array}{c}\text { Two piston tractor } \\
\text { wing engines } \\
\text { provide 4.89 }[\mathrm{hp}]\end{array}$ & $\begin{array}{c}\text { Two engines make } \\
\text { InView more safe }\end{array}$ \\
\hline \hline
\end{tabular}

Table 4 Performance comparison between Safat01 and InView

\begin{tabular}{c|c|c|c}
\hline \hline Parameter & Safat01 & InView $[4]$ & observation \\
\hline Maximum speed & $180[\mathrm{~km} / \mathrm{hr}]$ & $112[\mathrm{~km} / \mathrm{hr}]$ & \\
\hline Loiter speed & $150[\mathrm{~km} / \mathrm{hr}]$ & $24[\mathrm{~km} / \mathrm{hr}]$ & $\begin{array}{c}\text { This loiter speed is proper for Safat01 } \\
\text { to perform the mission }\end{array}$ \\
\hline Range & $200[\mathrm{~km}]$ & $700[\mathrm{~km}]$ & $\begin{array}{c}\text { Range is constrained by UAV control } \\
\text { technology }\end{array}$ \\
\hline Endurance & +16 hours & +7 hours & Safat01 fly with more endurance \\
\hline \hline
\end{tabular}

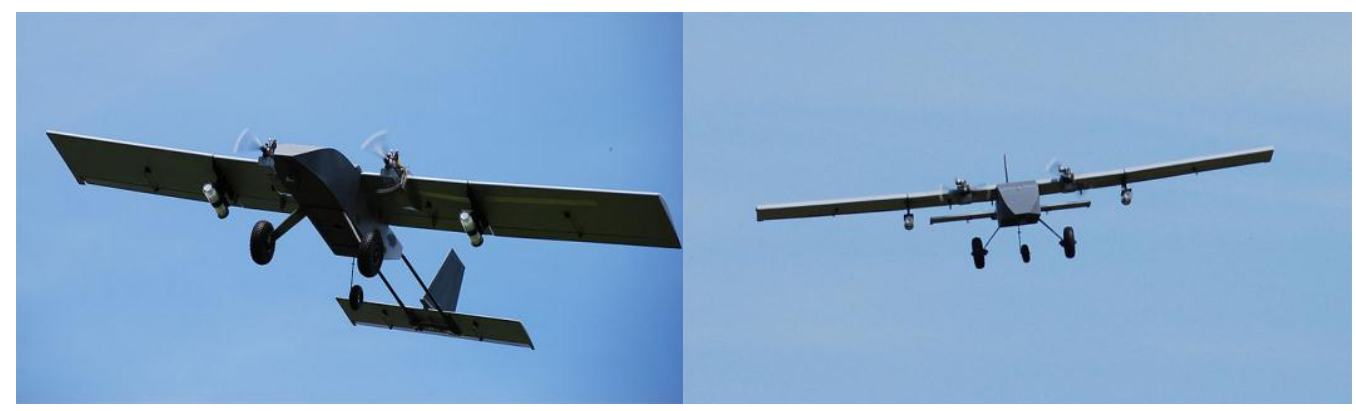

Figure 6 InView mining exploration UAV[8]

\section{Results and Discussion}

The analysis of Safat01 configuration from designing view point shows that components interfacing yield a good aerodynamical configuration for low speed light aircraft. The contribution of different parts in the A/C stability is reasonable. Safat01 doesn't perform high maneuvers and produce high induced drag. 
The comparison between Safat01 and InView yields the following:

1. Safat01 shows sufficient geometrical and performance capabilities, while it can carry more payload weight and is stable in low-level low-speed flying, so it had fulfilled most of the mission requirements.

2. The Safety of the aircraft is not big matter from the view point that it will be operated in desert inhabited operation environment.

\section{Conclusion and Recommendation}

- Mission of exploration needs to combine state-of-the-art miniaturized, low power, navigation sensors, communications electronics and digital flight automation electronics, with an efficient, reliable, low vibration engine, on a high performance air frame [9].

- Safat01 can fulfill these requirements efficiently with minor development.

- The reliability issue of Safat01 needs to be overcome during developing Safat01, since it has one engine while carrying very expensive payloads.

- The weight of Safat01 gives the possibilities of using it as multi-mission UAV.

- This methodology of designing helps to develop Safat01 in proper way, if there is an intention to operate it for other civilian missions.

\section{References}

[1] http://www.mining-technology.com/features/feature60074/

[2] Safat01 CFD Analysis Report

[3] Roskam, Airplane design, Part I: Preliminary Sizing of Airplanes, Roskam Aviation and Engineering Corporation, Ottawa, USA

[4] Daniel P. Raymer, Aircraft Design: A Conceptual Approach, American Institute of Aeronautics and Astronautics, Washington D.C. , USA.

[5] http://www.epmag.com/archives/features/481.htm

[6] Information in http://www.ingengineering.com/wp-content/uploads/Mining.pdf

[7] http://symposium.auvsi.org/auvsi11/public/SessionDetails.aspx?SessionId=255

[8] http://en.wikipedia.org/wiki/InView_Unmanned_Aircraft_System

[9] http://www.emacogroup.eu/UAV geological survey.pdf 